\title{
Aerobic Epoxidation of Low-Molecular-Weight and Polymeric Olefins by a Supramolecular Manganese Porphyrin Catalyst
}

\author{
Ivan Bernar, Floris P.J.T. Rutjes $\mathbb{D}^{\mathbb{D}}$, Johannes A.A.W. Elemans * and Roeland J.M. Nolte * $\mathbb{D}$ \\ Institute for Molecules and Materials, Radboud University, Heyendaalseweg 135, 6525 AJ Nijmegen, \\ The Netherlands; ibibernar@gmail.com (I.B.); F.Rutjes@science.ru.nl (F.P.J.T.R.) \\ * Correspondence: j.elemans@science.ru.nl (J.A.A.W.E.); r.nolte@science.ru.nl (R.J.M.N.); \\ Tel.: +31-024-36-52143 (R.J.M.N.)
}

Received: 29 January 2019; Accepted: 16 February 2019; Published: 21 February 2019

\begin{abstract}
We report on the highly efficient epoxidation of low-molecular-weight and polymeric olefins catalyzed by a supramolecular manganese porphyrin complex using molecular oxygen as an oxidant and an aldehyde as a co-reductant. At ambient temperature and under optimized reaction conditions, the catalyst showed high activity and stereoselectivity. The efficiency of the supramolecular manganese porphyrin was higher than that of a reference porphyrin catalyst, possibly because it was more stable under the applied reaction conditions. Mechanistic studies suggest that a manganese oxo porphyrin complex may be an intermediate in the epoxidation reaction.
\end{abstract}

Keywords: manganese porphyrins; aerobic oxidation; enzyme-like catalysis; processive catalysis

\section{Introduction}

Metalloporphyrins are amongst the vital chemical compounds that are crucial for life on earth. For example, the iron porphyrin complex heme plays a key role in the transport and delivery of molecular oxygen to animal tissues [1]. Over the years, great advances have been made in the synthesis of metalloporphyrin complexes [2] and their application in catalysis [3-5]. Our group has been active in the use of supramolecular metalloporphyrins as mimics of processive enzymes, e.g., DNA polymerase, which are biological catalysts that stay bound to a substrate while performing multiple rounds of catalysis [6]. We have previously shown that a U-shaped receptor based on glycoluril with a covalently attached manganese(III) porphyrin roof, $\mathrm{MnPC}$, can thread onto polymeric olefins (e.g., polybutadiene) and epoxidize them in a processive manner (Figure 1) [7-9]. To ensure that catalysis only takes place inside the cavity of the catalyst, a bulky axial ligand (4-tert-butylpyridine) was coordinated to the manganese center at the outside of the cage compound. The choice of the right oxidants was crucial for the effectiveness of the catalytic process. Thus, in the presence of oxygen donors such as iodosylbenzene (PhIO) or sodium hypochlorite $(\mathrm{NaOCl})$, the catalyst $\mathrm{MnPC}$ fully converted polybutadiene $\left(\mathrm{M}_{w} \approx 300 \mathrm{kDa}, 98 \%\right.$ cis $)$ into the corresponding polyepoxide within 2 hours [7]. More recently, we have reported on the use of molecular oxygen as the oxidant and an aldehyde as the co-reductant for the epoxidation of low-molecular-weight olefins, such as cis-stilbene, catalyzed by manganese porphyrin trimers [10]. The utilization of molecular oxygen is an attractive approach towards an environmentally friendly and cost-effective process for the production of epoxides [11]. This oxidant was introduced by Mukaiyama in the early 1990s and employed an aldehyde as the co-reductant and $\beta$-diketonate complexes of transition metals as catalysts [12-14]. Nowadays, a variety of catalysts are known [15], including metalloporphyrins $[5,10,16]$, which display a high catalytic performance for the aerobic oxidation of alkenes in the presence of an aldehyde, and some of them can even be used to produce chiral products [17-19]. 
We decided, therefore, to use this oxidant in the previously reported processive epoxidation of polymeric alkenes. In this paper we show that molecular oxygen in combination with an aldehyde reductant can be used as the oxidant in the epoxidation of low- and high-molecular-weight olefins catalyzed by a supramolecular manganese porphyrin cage catalyst.

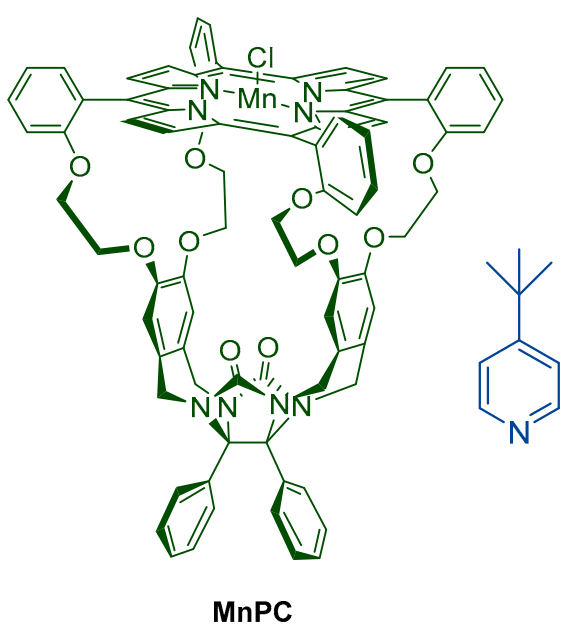

(a)

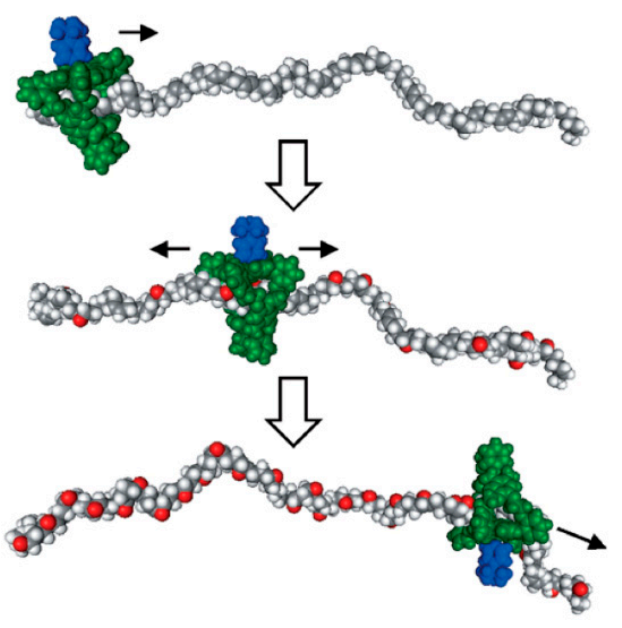

(b)

Figure 1. Processive epoxidation of polybutadiene by a manganese porphyrin cage catalyst [7]: (a) structure of the catalyst MnPC (green) and bulky axial ligand (blue); (b) epoxidation of the double bonds of polybutadiene by a process in which the macrocyclic catalyst slides along the polymer chain while epoxidizing its double bonds. Reproduced with permission from [6]. Copyright 2014, Wiley.

\section{Results and Discussion}

\subsection{Reaction Optimization}

Manganese porphyrin cage catalyst MnPC was prepared following a multistep procedure developed previously in our group, starting from tetrakis(2-hydroxyphenyl)porphyrin and diphenylglycoluril (for detailed information, see the Supporting Information). This catalyst was used in the epoxidation reactions in combination with a large excess of the bulky ligand 4-tert-butylpyridine (ligand:catalyst $=1000: 1$ ) in order to induce the formation of the catalytic species and to ensure that the subsequent catalytic reaction takes place inside the cavity of MnPC. Cyclohexene was used as a model compound to optimize the reaction conditions with molecular oxygen as the oxidant and isobutyraldehyde as a co-reductant.

In the presence of the isobutyraldehyde and in the absence of a catalyst, cyclohexene was converted into the corresponding epoxide, although in poor yield (up to 18\% conversion after 4 hours; Table 1, entry 1) [20]. The addition of manganese catalyst MnPC ( $0.5 \mathrm{~mol} \%$ with respect to the substrate) considerably enhanced the conversion up to $99 \%$ (93\% yield after isolation and purification) after 4 hours (Table 1, entry 4). Even when the amount of catalyst was only $0.01 \mathrm{~mol} \%$, an epoxide yield of $65 \%$ was obtained (Table 1, entry 2). Optimization studies revealed that catalyst loadings ranging from 0.1 to $0.5 \mathrm{~mol} \%$ were optimal for a smooth and fast product formation (Table 1, entries 3 and 4).

Subsequently, we studied the effect of the amount of the co-reductant isobutyraldehyde on the epoxidation process. Halving the amount of isobutyraldehyde led to a dramatic drop in conversion to $31 \%$, even in the presence of an additional $0.5 \mathrm{~mol} \%$ of the catalyst (Table 1 , entry 5 ). No reaction was observed in the absence of isobutyraldehyde, and only the starting materials were recovered (Table 1 , entry 6). These results show that the porphyrin cage catalyst cannot activate molecular oxygen without aldehyde as an oxygen reductant. 
Next, we investigated the performance of our catalytic system in various solvents (Table 1, entries 7-9). The reaction proceeded smoothly in halogenated hydrocarbons, such as DCM or DCE, because of the better solvation of the manganese porphyrin cage catalyst MnPC compared to that of MeCN or $\mathrm{MeOH}$. Moreover, because of its lower volatility, DCE was the preferred solvent to be used for the reaction running under $\mathrm{O}_{2}$-balloon flow.

Finally, we compared our catalytic system to the one in which the previously reported manganese meso-tetraphenylporphyrin chloride $\mathrm{MnTPPCl}$ was used (Table 1, entry 10) [21]. Both catalysts showed a similar catalytic activity, with almost quantitative conversion to cyclohexene oxide after $4 \mathrm{~h}$, indicating a similar nature of the epoxidation process for both catalysts.

Table 1. Aerobic epoxidation of cyclohexene catalyzed by manganese porphyrin cage catalyst MnPC in the presence of isobutyraldehyde. ${ }^{a}$

\begin{tabular}{|c|c|c|c|c|}
\hline & & $\begin{array}{l}(1 \mathrm{~atm}) \\
\mathrm{rCHO} \\
\stackrel{\mathrm{C} / 4-{ }^{t} \mathrm{BuPy}}{\longrightarrow}\end{array}$ & & \\
\hline Entry & Catalyst Loading (mol\%) & Solvent & Conversion (\%) ${ }^{b}$ & Yield $(\%)^{c}$ \\
\hline 1 & 0 & DCM & 18 & 15 \\
\hline 2 & 0.01 & DCM & 62 & 49 \\
\hline 3 & 0.1 & DCM & 96 & 84 \\
\hline 4 & 0.5 & DCM & $>99$ & 93 \\
\hline $5^{d}$ & 0.5 & DCM & 31 & 24 \\
\hline $6^{e}$ & 0.5 & DCM & 0 & 0 \\
\hline 7 & 0.5 & DCE & $>99$ & 92 \\
\hline 8 & 0.5 & $\mathrm{MeCN}$ & 89 & 83 \\
\hline 9 & 0.5 & $\mathrm{MeOH}$ & 56 & 42 \\
\hline $10^{f}$ & 0.5 & DCE & $>99$ & 91 \\
\hline
\end{tabular}

a Reaction conditions, unless stated otherwise: cyclohexene $(0.2 \mathrm{mmol})$, isobutyraldehyde $(2.0 \mathrm{mmol})$, 4-tert-butylpyridine $(1.0 \mathrm{mmol})$, solvent $(4 \mathrm{~mL}), \mathrm{O}_{2}$-balloon bubbling, $4 \mathrm{~h}, 23^{\circ} \mathrm{C} .{ }^{b}$ Based on the ${ }^{1} \mathrm{H}$ NMR spectrum of the crude reaction mixture. ${ }^{c}$ Isolated yield. ${ }^{d}$ Isobutyraldehyde $(0.5 \mathrm{mmol}) .{ }^{e}$ No isobutyraldehyde present. ${ }^{f} \mathrm{MnTPPCl}$ was used as the catalyst.

\subsection{Scope of the Aerobic Epoxidation of Olefins Catalyzed by Manganese Porphyrin Cage Compound MnPC}

To evaluate the scope of our catalytic system, we subjected various olefins to the optimized reaction conditions. As shown in Table 2, most substrates were smoothly converted into the corresponding epoxides with high conversion rates and excellent stereoselectivities.

Thus, 1-methylcyclohexene gave an excellent yield of the corresponding epoxide (94\%), similar to the results obtained with cyclohexene (Table 2, entry 1). The influence of steric effects as well as the electronic properties of the substituents were observed when styrene and its derivatives were epoxidized. Thus, after $4 \mathrm{~h}$ of reaction, the conversion rates of styrene, indene, and cis-stilbene were $95 \%, 89 \%$, and $86 \%$, respectively (Table 2, entries $2-4$ ), which are slightly lower values than those observed for cyclohexene. Moreover, trans-stilbene was found to be a significantly less reactive substrate compared to its cis-isomer (Table 2, entry 5). After $8 \mathrm{~h}$ of reaction time and using the standard catalytic protocol, the corresponding trans-stilbene oxide was formed with only $32 \%$ conversion. The addition of an extra $0.5 \mathrm{~mol} \%$ of catalyst and the stirring of the reaction mixture for $24 \mathrm{~h}$ resulted only in a slightly increased conversion to $45 \%$. This distinct difference between the reactivity of cisand trans-1,2-disubstituted olefins has already been reported for other manganese or iron porphyrin catalysts and further supports the role of steric and electronic factors on the effectiveness of the epoxidation reaction $[22,23]$. 
Table 2. Scope of the aerobic epoxidation of olefins catalyzed by manganese porphyrin catalyst MnPC. ${ }^{a}$

Entry

a Reaction conditions: olefin $(0.2 \mathrm{mmol})$, isobutyraldehyde $(2.0 \mathrm{mmol})$, 4-tert-butyl-pyridine $(1.0 \mathrm{mmol})$, MnPC catalyst $(1.0 \mu \mathrm{mol}), \mathrm{DCE}(4 \mathrm{~mL}), \mathrm{O}_{2}$-balloon bubbling, $23^{\circ} \mathrm{C} .{ }^{b}$ Yields and cis/trans ratios were determined by ${ }^{1} \mathrm{H}$ NMR spectroscopy using furan as an internal standard. ${ }^{c} \mathrm{MnTPPCl}$ was used as the catalyst. ${ }^{d} 1.0 \mathrm{~mol} \%$ of catalyst MnPC was used.

For both the epoxidation of cis- and trans-stilbene we observed excellent stereoselectivities. Thus, the epoxidation of cis-stilbene proceeded with a 95:5 cis/trans stereoselectivity, whereas for trans-stilbene the trans-epoxide was almost exclusively formed. Interestingly, the corresponding stereoselectivities and yields were somewhat lower when the reference catalyst $\mathrm{MnTPPCl}$ was used (90:10 cis/trans ratio, 86\% yield for cis-stilbene and 5:95 cis/trans ratio, 30\% yield for trans-stilbene). Similar results were obtained for the epoxidation of cinnamyl acetate (Table 2, entry 6) - the reaction using MnPC as the catalyst gave a yield of $67 \%$ with excellent stereoselectivity ( $>99 \%$ trans-isomer), while the reaction using MnTPPCl led to 61\% yield and 3:97 cis/trans stereoselectivity. These results may indicate the presence of a "cage effect" for the catalyst MnPC, i.e., the olefin substrate experiences additional steric hindrance when it approaches the metal-oxo species within the confined space of the macrocyclic receptor, reducing its conversion and improving its stereoselectivity. Moreover, the lower epoxide yields in the control experiment with MnTPPCl tentatively suggest that the better performance of MnPC could be the result of a higher stability of this catalyst as compared to that of MnTPPCl.

In line with our hypothesis that the epoxidation takes place inside the cavity of the catalyst rather than on the outside, the catalytic epoxidation of cis-cyclooctene proceeded rather slowly with MnPC compared to that of the reference substrate cyclohexene (Table 2, entry 7, after 24 h only $48 \%$ 
conversion was achieved). Further support for the "cage effect" is the fact that the epoxidation of cis-cyclooctene under the same reaction conditions, but using $\mathrm{MnTPPCl}$ as the catalyst, resulted in $89 \%$ yield after only $8 \mathrm{~h}$. Finally, the epoxidation of olefins in linear chains-for example, allylbenzene and non-1-ene-smoothly proceeded with high conversions (Table 2, entries 8 and 9). The similar epoxidation results for both substrates show that when the $\mathrm{C}=\mathrm{C}$ double bond in the linear chain is at a terminal position the reactivity is not very much affected.

\subsection{Aerobic Epoxidation of Polymers Catalyzed by Manganese Porphyrin Cage Catalyst MnPC}

The results obtained for the aerobic epoxidation of low-molecular-weight olefins catalyzed by the supramolecular catalyst MnPC encouraged us to further explore the processive catalytic epoxidation of polymers. We used commercially available polybutadiene $\mathrm{A}\left(\mathrm{M}_{w}=200,000-300,000 ; 98 \%\right.$ cis $)$, polybutadiene B $\left(\mathrm{M}_{w}=5,000 ; 80 \%\right.$ cis- and trans-1,4, 20\% vinyl), and polyisoprene $(97 \%$ cis $)$ as polymeric substrates for the epoxidation studies. Additionally, control experiments were performed with MnTPPCl to compare the effectiveness of the reaction for both catalysts (Table 3).

Table 3. Aerobic epoxidation of polymers catalyzed by manganese porphyrin cage catalyst MnPC and reference catalyst MnTPP in the presence of isobutyraldehyde. ${ }^{a}$

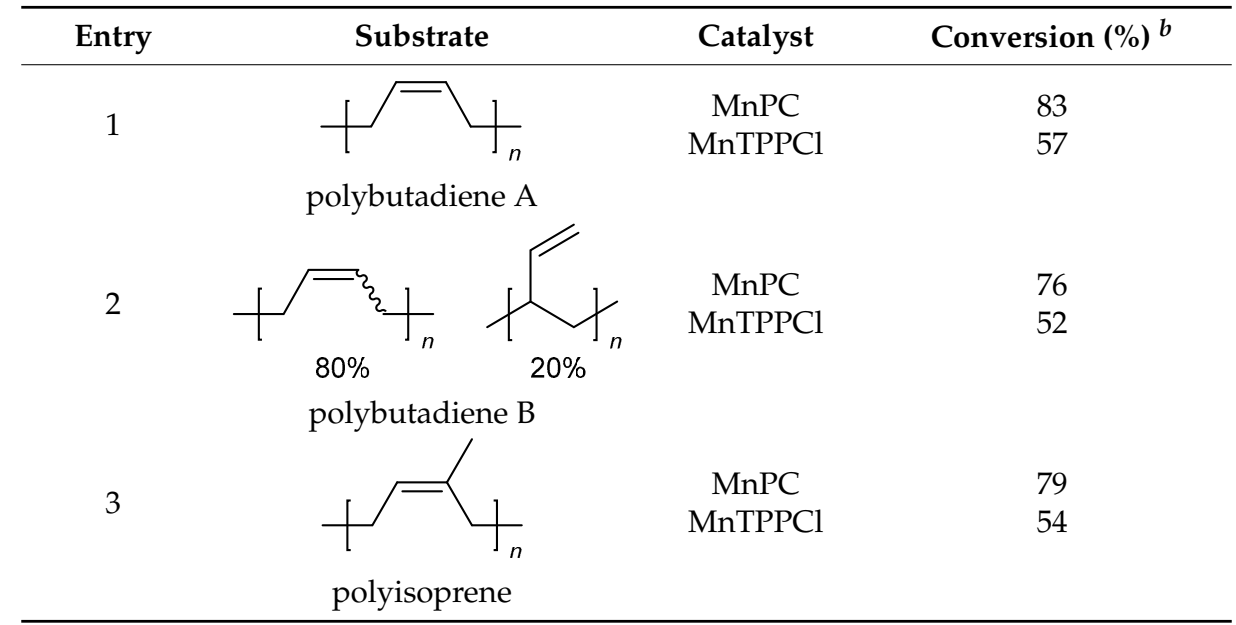

${ }^{a}$ Reaction conditions: polymer $(0.2 \mathrm{mmol}$ of $\mathrm{C}=\mathrm{C})$, isobutyraldehyde $(2.0 \mathrm{mmol})$, 4-tert-butylpyridine $(1.0 \mathrm{mmol})$, DCE (4 mL), $\mathrm{O}_{2}$-balloon bubbling, $8 \mathrm{~h}, 23{ }^{\circ} \mathrm{C} .{ }^{b}$ Conversions were determined by ${ }^{1} \mathrm{H}$ NMR spectroscopy.

After $8 \mathrm{~h}, 83 \%$ of the alkene moieties in polybutadiene A were converted by MnPC to epoxides, as was judged by ${ }^{1} \mathrm{H}$ NMR (Table 3, entry 1 ). Based on the chemical shifts of the starting material $(\delta=5.42 \mathrm{ppm}$, olefinic cis-polybutadiene proton) and the epoxide product ( $\delta=3.01 \mathrm{ppm}$, cis-proton), no trans-epoxide ( $\delta=2.72 \mathrm{ppm}$, trans-proton in the epoxidized molecule) was formed [24]. This result is different when compared to our previous studies with iodosylbenzene as the oxidant. In the latter case, an appreciable amount of trans-epoxide was generated [9]. According to ${ }^{13} \mathrm{C}$ NMR spectroscopy, possible side products containing hydroxyl or ester groups (formed as a result of further epoxy group conversion) were not formed in detectable amounts [25]. The control reaction using MnTPPCl as the catalyst also proceeded with the exclusive formation of the cis-polyepoxide, although with a much lower conversion (57\%). Furthermore, we investigated how polybutadiene B behaved as a substrate for the aerobic epoxidation (Table 3, entry 2). Due to the presence of vinyl groups along the chain, this substrate is sterically more crowded than polybutadiene A, and therefore might slow down the rate of movement of MnPC along the polymeric chain, if such a process occurs. Our studies revealed that the reaction rate of this polymer was similar to that of polybutadiene A with up to $76 \%$ conversion after $8 \mathrm{~h}$. Again, the epoxidation of polybutadiene B catalyzed by $\mathrm{MnTPPCl}$ was slower, reaching only $52 \%$ conversion. Finally, cis-1,4-polyisoprene was subjected to the catalytic epoxidation reaction (Table 3, entry 3). In this case the degree of epoxidation was determined by comparing the relative areas of 
the signals in the ${ }^{1} \mathrm{H}$ NMR spectra at $\delta=5.11 \mathrm{ppm}$ (olefinic cis-1,4-polyisoprene proton) and $\delta=2.81$ ppm (proton in the epoxidized molecule) [26]. Similar to what was observed for the epoxidation of the previous polymeric substrates, the conversion of cis-1,4-polyisoprene with MnPC after $8 \mathrm{~h}$ was higher than that with $\mathrm{MnTPPCl}$ (79\% and 54\%, respectively). These results are again in favor of the suggestion that $\mathrm{MnTPPCl}$ is less stable under the reaction conditions compared to MnPC, in line with our previous studies [27].

\subsection{Plausible Mechanism for the Aerobic Epoxidation Catalyzed by Manganese Porphyrin Cage Catalyst $\mathrm{MnPC}$}

Multiple reports of metalloporphyrin-catalyzed oxidations suggest that high-valent metal intermediates play key roles in the oxidation of organic substrates [28-30]. Particularly, our previous work on manganese porphyrin-catalyzed epoxidations suggests the formation of catalytically active high-valent manganese(IV or V) oxo porphyrins [9,10,31,32]. The presence of such a reactive species was also confirmed for catalyst MnPC by monitoring the changes in the UV-vis spectra during the oxidation of cyclohexene. Spectral changes of the reaction mixture were recorded with intervals of $1 \mathrm{~h}$ (Figure 2a). As the reaction proceeded, the absorbance of the Soret band at $480 \mathrm{~nm}$ gradually decreased, accompanied by decreases in the absorbance of the Q-bands at $581 \mathrm{~nm}$ and $617 \mathrm{~nm}$. At the same time, the color of the reaction mixture changed from green to yellow, indicating the gradual decomposition of the catalyst. We also recorded the changes in the UV-vis spectra of the reaction mixture in the absence of the substrate (Figure $2 b$ ). In that case, we also observed a decrease in the absorbance of the Soret and Q bands, but with a concomitant emergence of two new bands at 428 and $525 \mathrm{~nm}$. These new bands provide evidence for the formation of an active manganese oxo species [33]. After the mixture was left to stand, the intensities of these bands gradually decreased, accompanied by a color change from brown to yellow. As proposed above, this might be due to the degradation of the catalyst over time.

It is generally accepted that the formation of manganese oxo porphyrins in the presence of molecular oxygen and aldehyde as a reductant is a free radical reaction [34]. To investigate if this free radical mechanism also applies for the catalyst MnPC, a radical trapping experiment was conducted. Hence, butylated hydroxytoluene (BHT), a well-known radical scavenger, was added to the reaction mixture with cyclohexene as the substrate (Scheme 1). Only a trace of cyclohexene oxide was detected, indicating that radical species are also involved in the epoxidation reaction catalyzed by MnPC.

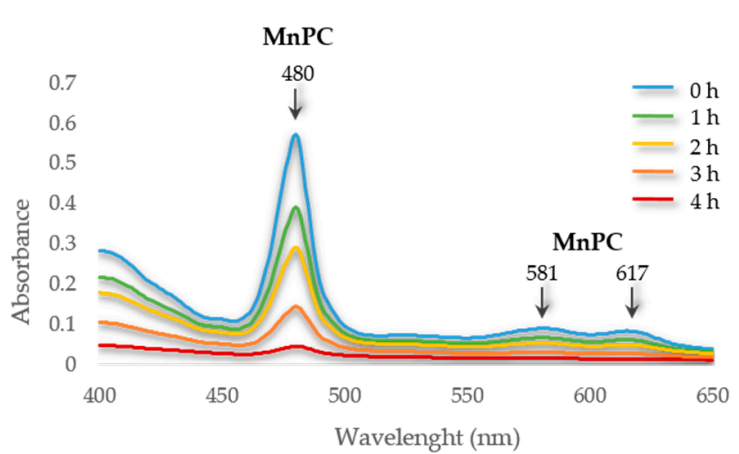

(a)

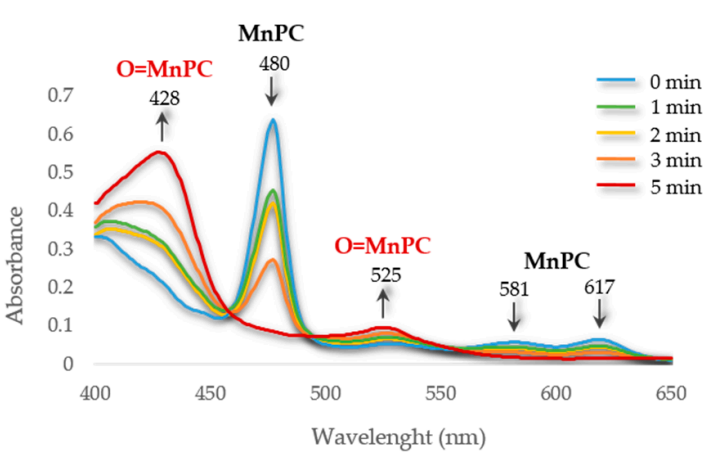

(b)

Figure 2. In situ UV-vis spectra of the manganese porphyrin cage catalyst MnPC during the aerobic epoxidation of cyclohexene: (a) in the presence of cyclohexene (cyclohexene $(0.2 \mathrm{mmol})$, isobutyraldehyde (2.0 mmol), 4-tert-butyl-pyridine $(1.0 \mathrm{mmol}), \mathrm{MnPC}$ catalyst $(1.0 \mu \mathrm{mol}), \mathrm{DCE}(4 \mathrm{~mL})$, $\mathrm{O}_{2}$-balloon bubbling, $\left.23{ }^{\circ} \mathrm{C}\right) ;(\mathbf{b})$ in the absence of cyclohexene (isobutyraldehyde $(0.1 \mathrm{mmol})$, 4-tert-butyl-pyridine ( $0.5 \mathrm{mmol}), \mathrm{MnPC}$ catalyst $(2.0 \mu \mathrm{mol}), \mathrm{DCE}(4 \mathrm{~mL}), \mathrm{O}_{2}$-balloon bubbling, $\left.23^{\circ} \mathrm{C}\right)$. 


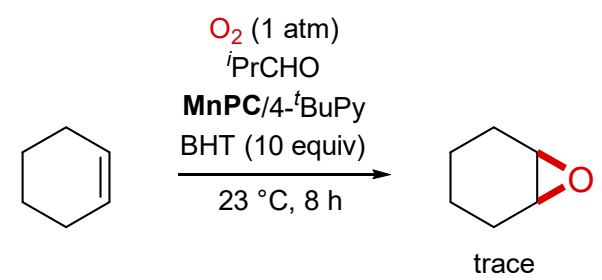

Scheme 1. Control experiment using BHT as a radical scavenger.

Based on the observed results and previous reports, a plausible mechanism can be proposed for the aerobic epoxidation of olefins in the presence of MnPC and isobutyraldehyde (Scheme 2). First, an acyl radical is formed via a hydrogen atom abstraction from the aldehyde. This step can occur without the mediation of the manganese porphyrin; however, the conversion of cyclohexene in the absence of the catalyst is rather low (compare entries 1 and 4, Table 1), suggesting that the manganese porphyrin plays a role. A subsequent reaction between the acyl radical and $\mathrm{O}_{2}$ generates an acyl peroxy radical. Hydrogen atom abstraction from a second equivalent of aldehyde produces a peracid and another acyl radical. Once the peracid is formed, it decomposes in the presence of manganese porphyrin. One of the products of this reaction is a catalytically active high-valent manganese oxo species, either a $\mathrm{Mn}(\mathrm{IV})$ oxo or $\mathrm{Mn}(\mathrm{V})$ oxo complex, which can readily oxidize an olefin to an epoxide while it is being reduced itself to a manganese(II) complex. This process repeats until all manganese oxo species are decomposed to $\mu$-oxo dimeric manganese porphyrin and other catalytically inactive species [35], which can be judged by the change in color of the reaction mixture (light yellow solution).

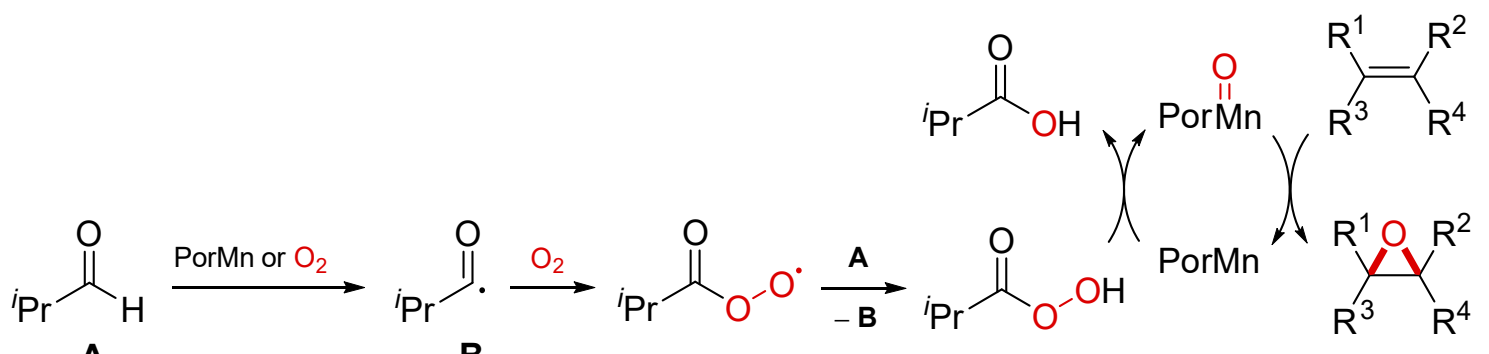

A

B

Scheme 2. Mechanism proposed for the aerobic epoxidation olefins catalyzed by manganese porphyrins using molecular oxygen as the oxidant and isobutyraldehyde as a co-reductant.

\section{Materials and Methods}

\subsection{Experimental Section}

Dichloromethane was distilled over $\mathrm{CaH}_{2}$ under nitrogen just before use. All other solvents and chemicals were used as received from the supplier without further purification. Polybutadiene A $\left(\mathrm{M}_{w}=200,000-300,000,98 \%\right.$ cis $)$, polybutadiene B ( $\mathrm{M}_{w}=5000 ; 80 \%$ cis- and trans $-1,4,20 \%$ vinyl), and polyisoprene ( $97 \%$ cis) were purchased from Sigma-Aldrich Co. (St. Louis, MO, USA) and used without further purification. Flash chromatography was performed over silica gel. UV-vis spectra were recorded in quartz cuvettes using a Cary 100 Conc (Varian, Middelburg, Netherlands) UV-vis spectrometer. All NMR spectra were collected on a Bruker $500 \mathrm{MHz}$ Avance III spectrometer (Bruker, Billerica, MA, USA) equipped with a Prodigy BB cyroprobe in deuterated chloroform $\left(\mathrm{CDCl}_{3}\right)$ unless stated otherwise. Manual phase correction and automatic baseline correction were applied to all spectra. Reported chemical shifts are in positive ppm downfield and negative ppm upfield from the internal tetramethylsilane standard (0.00 ppm). ${ }^{1} \mathrm{H}$ NMR spectra were obtained using 128 scans with a relaxation delay of $4 \mathrm{~s} .{ }^{13} \mathrm{C}\left\{{ }^{1} \mathrm{H}\right\}$ NMR spectra were obtained using 1024 scans with a relaxation delay of $2 \mathrm{~s}$. Ultraviolet-visible (UV-vis) absorbance spectra were recorded on Jasco J-650 spectrometer (Jasco, Easton, MD, USA) at ambient temperature. Maldi-TOF mass spectroscopy was performed on a Bruker Biflex III spectrometer (Bruker, Billerica, MA, USA). 


\subsection{Synthesis of Manganese Porphyrin Cage Catalyst Mn1}

The experimental procedure for the preparation of manganese porphyrin cage catalyst Mn1 has been reported before [36] and can be found in the supporting information to this manuscript.

\subsection{General Procedure for the Catalytic Epoxidation of Olefins to Epoxides}

Dioxygen was bubbled through a solution of olefin $(0.2 \mathrm{mmol})$, isobutyraldehyde $(2.0 \mathrm{mmol})$, 4-tert-butyl-pyridine (1.0 mmol), and manganese porphyrin (either MnPC or MnTPPCl) $(1.0 \mu \mathrm{mol})$ in 1,2-dichloroethane $(4 \mathrm{~mL})$ at $23{ }^{\circ} \mathrm{C}$. Once the reaction was completed $\left(4-24 \mathrm{~h}\right.$, as checked by TLC or ${ }^{1} \mathrm{H}$ NMR), the solvent was removed under vacuum and the crude reaction mixture was analyzed by ${ }^{1} \mathrm{H}$ NMR to determine the yield of the epoxide and the cis:trans ratio. Signal assignment of protons of the products in the ${ }^{1} \mathrm{H}$ NMR spectra of the reaction mixture were based on bibliographical data and yields were calculated by the integration of the corresponding peaks, using furan as an internal standard, which was added to the deuterated solvent [37].

\subsection{General Procedure for the Catalytic Epoxidation of Polyenes to Epoxides}

Dioxygen was bubbled through a solution of polymer $(0.2 \mathrm{mmol}, \mathrm{C}=\mathrm{C})$, isobutyraldehyde (2.0 mmol), 4-tert-butyl-pyridine (1.0 mmol), and manganese porphyrin (either $\mathrm{MnPC}$ or MnTPPCl) $(1.0 \mu \mathrm{mol})$ in 1,2 -dichloroethane $(4 \mathrm{~mL})$ at $23^{\circ} \mathrm{C}$. Once the reaction was completed $(8 \mathrm{~h}$, as checked by TLC or ${ }^{1} \mathrm{H}$ NMR) the solvent was removed under vacuum and the crude reaction mixture was analyzed by ${ }^{1} \mathrm{H}$ NMR to determine the conversion of the alkene functions into epoxides. Signal assignment of protons of the products in the ${ }^{1} \mathrm{H}$ NMR spectra of the reaction mixture were based on bibliographical data and conversions were calculated by the integration of the corresponding peaks of the starting material and final products.

\section{Conclusions}

In summary, a highly efficient procedure for the epoxidation of olefins with the manganese porphyrin cage complex MnPC as a catalyst, isobutyraldehyde as a co-reductant, and dioxygen as an oxidant was developed. The effects of the amounts of aldehyde and catalyst, as well as the use of various solvents, were studied and optimized. The supramolecular catalytic system conferred higher activity and stereoselectivity to the epoxidation of olefines compared to the system in which $\mathrm{MnTPPCl}$ was used as the catalyst. Epoxidation studies with polybutadiene and polyisoprene showed that the MnPC catalytic system also smoothly converts these polymers into polyepoxides with good conversions. For the catalytic aerial epoxidation, a reaction mechanism involving a radical process with the intermediate formation of a manganese oxo species was proposed. The formation of the high-valent manganese porphyrin species was confirmed by UV-vis spectroscopy and the radical character of the reaction by a radical trapping experiment. The catalytic reaction described in this work could pave the way towards the economical and environmentally friendly production of simple and polymeric epoxides.

Supplementary Materials: The following are available online at http:/ /www.mdpi.com/2073-4344/9/2/195/s1, Scheme S1: Preparation of manganese porphyrin cage catalyst MnPC. Figure S1: ${ }^{1} \mathrm{H}$ NMR spectrum of a sample of the crude reaction mixture of a catalytic epoxidation of polybutadiene A. Figure S2: ${ }^{1} \mathrm{H}$ NMR spectrum of a sample of the crude reaction mixture of a catalytic epoxidation of polyisoprene. Figure S3: In situ UV-vis spectra of the manganese porphyrin cage catalyst MnPC during the aerobic epoxidation of cyclohexene. Figure S4: In situ $\mathrm{UV}$-vis spectra of the manganese porphyrin cage catalyst MnPC under the same conditions but in the absence of cyclohexene.

Author Contributions: Conceptualization, I.B, J.A.A.W.E., and R.J.M.N.; methodology, I.B.; software, I.B.; validation, I.B.; formal analysis, I.B.; investigation, I.B.; resources, I.B.; data curation, I.B.; writing and original draft preparation, I.B.; writing, review and editing, J.A.A.W.E., F.P.J.T.R., and R.J.M.N.; visualization, I.B.; supervision, J.A.A.W.E., F.P.J.T.R., and R.J.M.N.; project administration, R.J.M.N.; funding acquisition, R.J.M.N. 
Funding: R.J.M.N. acknowledges support from the European Research Council (ERC Advanced Grant ENCOPOL-74092) and from the Dutch National Science Organization NWO (Gravitation program 024.001.035).

Conflicts of Interest: The authors declare no conflict of interest.

\section{References}

1. Poulos, T.L. Heme Enzyme Structure and Function. Chem. Rev. 2014, 114, 3919-3962. [CrossRef] [PubMed]

2. Hiroto, S.; Miyake, Y.; Shinokubo, H. Synthesis and Functionalization of Porphyrins through Organometallic Methodologies. Chem. Rev. 2017, 117, 2910-3043. [CrossRef] [PubMed]

3. Huang, X.; Groves, J.T. Oxygen Activation and Radical Transformations in Heme Proteins and Metalloporphyrins. Chem. Rev. 2018, 118, 2491-2553. [CrossRef] [PubMed]

4. Lua, H.; Zhang, X.P. Catalytic C-H Functionalization by Metalloporphyrins: Recent Developments and Future Directions. Chem. Soc. Rev. 2011, 40, 1899-1909. [CrossRef]

5. Barona-Castaño, J.C.; Carmona-Vargas, C.C.; Brocksom, T.J.; De Oliveira, K.T. Porphyrins as Catalysts in Scalable Organic Reactions. Molecules 2016, 21, 310. [CrossRef]

6. Van Dongen, S.F.M.; Elemans, J.A.A.W.; Rowan, A.E.; Nolte, R.J.M. Processive Catalysis. Angew. Chem. Int. Ed. 2014, 53, 11420-11428. [CrossRef] [PubMed]

7. Thordarson, P.; Bijsterveld, E.J.A.; Rowan, A.E.; Nolte, R.J.M. Epoxidation of Polybutadiene by a Topologically Linked Catalyst. Nature 2003, 424, 915-918. [CrossRef]

8. Coumans, R.G.E.; Elemans, J.A.A.W.; Nolte, R.J.M.; Rowan, A.E. Processive Enzyme Mimic: Kinetics and Thermodynamics of the Threading and Sliding Process. Proc. Natl. Acad. Sci. USA 2006, 103, 19647-19651. [CrossRef]

9. Monnereau, C.; Ramos, P.H.; Deutman, A.B.C.; Elemans, J.A.A.W.; Nolte, R.J.M.; Rowan, A.E. Porphyrin Macrocyclic Catalysts for the Processive Oxidation of Polymer Substrates. J. Am. Chem. Soc. 2010, 132, 1529-1531. [CrossRef]

10. De Torres, M.; van Hameren, R.; Nolte, R.J.M.; Rowan, A.E.; Elemans, J.A.A.W. Photocatalytic Oxidation of Stilbene by Self-Assembled Stacks of Manganese Porphyrins. Chem. Commun. 2013, 49, 10787-10789. [CrossRef]

11. Pereira, M.M.; Dias, L.D.; Calvete, M.J.F. Metalloporphyrins: Bioinspired Oxidation Catalysts. ACS Catal. 2018, 8, 10784-10808. [CrossRef]

12. Yamada, T.; Takai, T.; Rhode, O.; Mukaiyama, T. Direct Epoxidation of Olefins Catalyzed by Nickel(II) Complexes with Molecular Oxygen and Aldehydes. Bull. Chem. Soc. Jpn. 1991, 64, 2109-2117. [CrossRef]

13. Yamada, T.; Imagawa, K.; Nagata, T.; Mukaiyama, T. Enantioselective Epoxidation of Unfunctionalized Olefins with Molecular Oxygen and Aldehyde Catalyzed by Optically Active Manganese(III) Complexes. Chem. Lett. 1992, 21, 2231-2234. [CrossRef]

14. Nagata, T.; Imagawa, K.; Yamada, T.; Mukaiyama, T. Enantioselective Aerobic Epoxidation of Acyclic Simple Olefins Catalyzed by the Optically Active $\beta$-Ketoiminato Manganese(III) Complex. Chem. Lett. 1994, 23, 1259-1262. [CrossRef]

15. Shi, Z.; Zhang, C.; Tanga, C.; Jiao, N. Recent Advances in Transition-Metal Catalyzed Reactions Using Molecular Oxygen as the Oxidant. Chem. Soc. Rev. 2012, 41, 3381-3430. [CrossRef] [PubMed]

16. Kuijpers, P.F.; Otte, M.; Dürr, M.; Ivanović-Burmazović, I.; Reek, J.N.H.; de Bruin, B. A Self-Assembled Molecular Cage for Substrate-Selective Epoxidation Reactions in Aqueous Media. ACS Catal. 2016, 6, 3106-3112. [CrossRef]

17. Farokhi, A.; Berijani, K.; Hosseini-Monfared, H. Manganes-Porphyrin as Efficient Enantioselective Catalyst for Aerobic Epoxidation of Olefins. Catal. Lett. 2018, 148, 2608-2618. [CrossRef]

18. Berijani, K.; Farokhi, A.; Hosseini-Monfared, H.; Janiak, C. Enhanced Enantioselective Oxidation of Olefins Catalyzed by Mn-Porphyrin Immobilized on Graphene Oxide. Tetrahedron 2018, 74, 2202-2210. [CrossRef]

19. Farokhi, A.; Hosseini-Monfared, H. Highly Efficient Asymmetric Epoxidation of Olefins with a Chiral Manganese-Porphyrin Covalently Bound to Mesoporous SBA-15: Support Effect. J. Catal. 2017, 352, $229-238$. [CrossRef]

20. For similar results see: Zhou, X.-T.; Tang, Q.-H.; Ji, H.-B. Remarkable Enhancement of Aerobic Epoxidation Reactivity for Olefins Catalyzed by $\mu$-oxo-Bisiron(III) Porphyrins under Ambient Conditions. Tetrahedron Lett. 2009, 50, 6601-6605. [CrossRef] 
21. Zhou, X.-T.; Ji, H.-B.; Xu, J.-C.; Pei, L.-X.; Wang, L.-F.; Yao, X.-D. Enzymatic-like Mediated Olefins Epoxidation by Molecular Oxygen under Mild Conditions. Tetrahedron Lett. 2007, 48, 2691-2695. [CrossRef]

22. Groves, J.T.; Nemo, T.E. Epoxidation Reactions Catalyzed by Iron Porphyrins. Oxygen Transfer from Iodosylbenzene. J. Am. Chem. Soc. 1983, 105, 5786-5791. [CrossRef]

23. Battioni, P.; Renaud, J.P.; Bartoli, J.F.; Reina-Artiles, M.; Fort, M.; Mansuy, D. Monooxygenase-like Oxidation of Hydrocarbons by $\mathrm{H}_{2} \mathrm{O}_{2}$ Catalyzed by Manganese Porphyrins and Imidazole: Selection of the Best Catalytic System and Nature of the Active Oxygen Species. J. Am. Chem. Soc. 1988, 110, 8462-8470. [CrossRef]

24. Aguiar, M.; Cabral de Menezes, S.; Akcelrud, L. Configurational Double Bond Selectivity in the Epoxidation of Hydroxy-terminated Polybutadiene with m-Chloroperbenzoic Acid. Macromol. Chem. Phys. 1994, 195, 3937-3948. [CrossRef]

25. Gan, L.-H.; Ng, S.-C. Kinetic Studies of the Performic Acid Epoxidation of Natural Rubber Latex Stabilized by Cationic Surfactant. Eur. Polym. J. 1986, 22, 573-576. [CrossRef]

26. Davies, C.K.L.; Wolfe, S.V.; Gelling, I.R.; Thomas, A.G. Strain Crystallization in Random Copolymers Produced by Epoxidation of cis 1,4-Polyisoprene. Polymer 1983, 24, 107-113. [CrossRef]

27. Elemans, J.A.A.W.; Bijsterveld, E.J.A.; Rowan, A.E.; Nolte, R.J.M. A Host-Guest Epoxidation Catalyst with Enhanced Activity and Stability. Chem. Commun. 2000, 24, 2443-2444. [CrossRef]

28. Nunes, G.S.; Mayer, I.; Toma, H.E.; Araki, K. Kinetics and Mechanism of Cyclohexane Oxidation Catalyzed by Supramolecular Manganese(III) Porphyrins. J. Catal. 2005, 236, 55-61. [CrossRef]

29. Fukuzumi, S.; Fujioka, N.; Kotani, H.; Ohkubo, K.; Lee, Y.-M.; Nam, W. Mechanistic Insights into Hydride-Transfer and Electron-Transfer Reactions by a Manganese(IV)-Oxo Porphyrin Complex. J. Am. Chem. Soc. 2009, 131, 17127-17134. [CrossRef]

30. Baglia, R.A.; Zaragoza, J.P.T.; Goldberg, D.P. Biomimetic Reactivity of Oxygen-Derived Manganese and Iron Porphyrinoid Complexes. Chem. Rev. 2017, 117, 13320-13352. [CrossRef]

31. Den Boer, D.; Li, M.; Habets, T.; Iavicoli, P.; Rowan, A.E.; Nolte, R.J.M.; Speller, S.; Amabilino, D.B.; De Feyter, S.; Elemans, J.A.A.W. Detection of Different Oxidation States of Individual Manganese Porphyrins during their Oxidation with Oxygen at a Solid/Liquid Interface. Nat. Chem. 2013, 5, 621-627. [CrossRef] [PubMed]

32. Thomassen, P.J.; Varghese, S.; Bijsterveld, E.J.A.; Thordarson, P.; Elemans, J.A.A.W.; Rowan, A.E.; Nolte, R.J.M. A Double-Cavity-Containing Porphyrin Host as a Highly Stable Epoxidation Catalyst. Eur. J. Org. Chem. 2015, 5246-5253. [CrossRef]

33. Groves, J.T.; Stern, M.K. Synthesis, Characterization, and Reactivity of Oxomanganese(IV) Porphyrin Complexes. J. Am. Chem. Soc. 1988, 110, 8628-8638. [CrossRef]

34. Nam, W.; Kim, H.J.; Kim, S.H.; Ho, R.Y.N.; Valentine, J.S. Metal Complex-Catalyzed Epoxidation of Olefins by Dioxygen with Co-Oxidation of Aldehydes. A Mechanistic Study. Inorg. Chem. 1996, 35, 1045-1049. [CrossRef] [PubMed]

35. Smegal, J.A.; Schardt, B.C.; Hill, C.L. Isolation, Purification, and Characterization of Intermediate (Iodosylbenzene)metalloporphyrin Complexes from the (Tetraphenylporphinato)manganese(III)Iodosyl-benzene Catalytic Hydrocarbon Functionalization System. J. Am. Chem. Soc. 1983, 105, 3510-3515. [CrossRef]

36. Elemans, J.A.A.W.; Bijsterveld, E.J.A.; Rowan, A.E.; Nolte, R.J.M. Manganese Porphyrin Hosts as Epoxidation Catalysts-Activity and Stability Control by Axial Ligand Effects. Eur. J. Org. Chem. 2007, 5, 751-757. [CrossRef]

37. Pereira, A.; Martín, C.; Maya, C.; Belderrain, T.R.; Pérez, P.J. An Effective Dual Copper- and Sulfide-Catalytic System for the Epoxidation of Aldehydes with Phenyldiazomethane. Adv. Synth. Catal. 2013, 355, $2942-2951$. [CrossRef]

(C) 2019 by the authors. Licensee MDPI, Basel, Switzerland. This article is an open access article distributed under the terms and conditions of the Creative Commons Attribution (CC BY) license (http:/ / creativecommons.org/licenses/by/4.0/). 